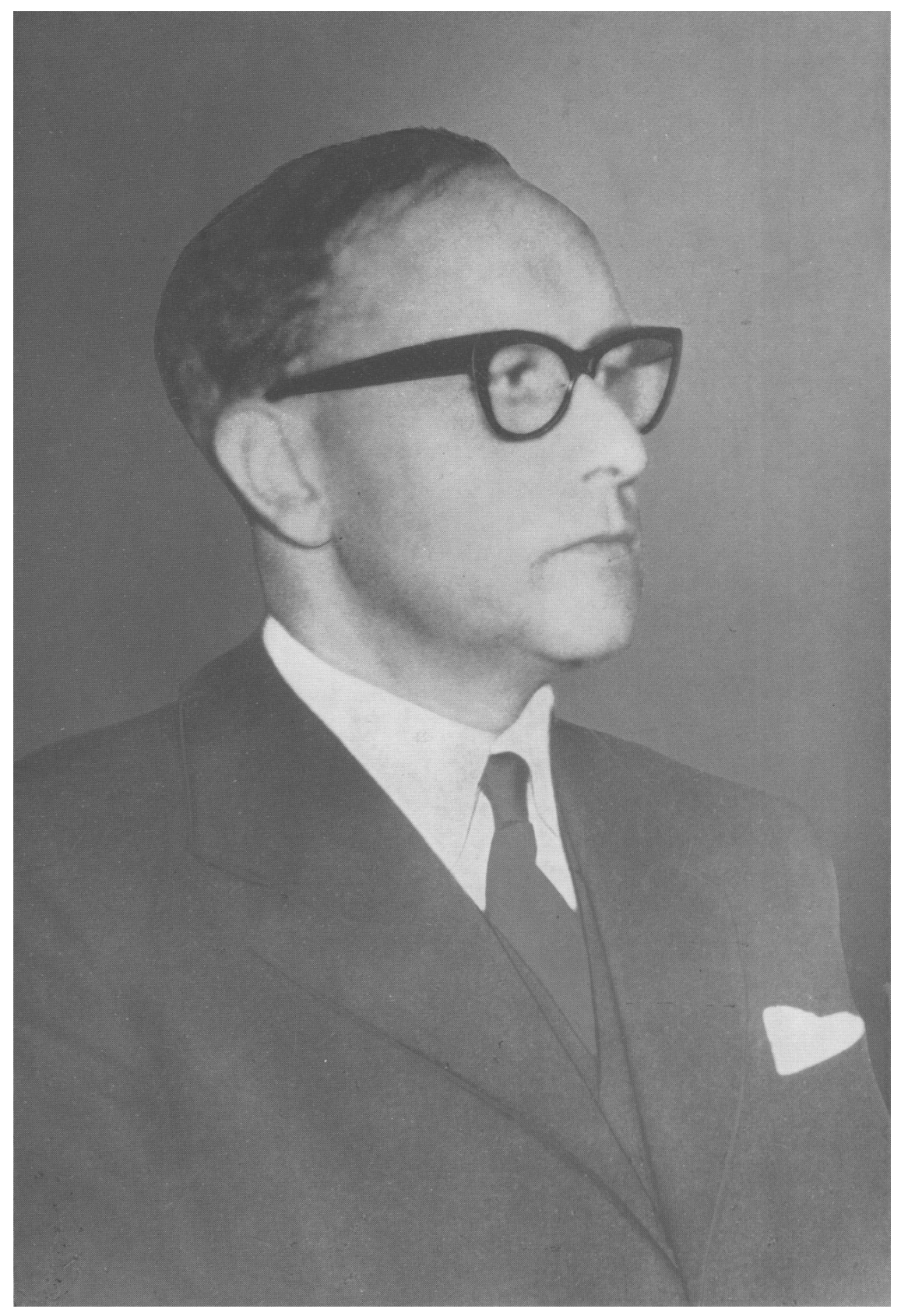




\section{PROFESSOR A. J. C. RÜTER †}

We deeply regret to announce the sudden death of our Director, Professor A. J.C. Rüter, on August I I.

From the foundation, in 1935, of the Internationaal Instituut voor Sociale Geschiedenis Dr. Rüter took an active part in its work. In the same year appeared his doctoral thesis on "The Railway Strikes of 1903: A Mirror of the Labour Movement in the Netherlands", which established his fame as an outstanding social historian; it was followed by several other publications in the field of Dutch history. In 1953 he succeeded Professor Posthumus as Director of the Institute.

Professor Rüter's qualities as a scholar and his achievements as an organizer will be made the subject of two commemorative contributions to be published in the next issue of this journal.

It is only appropriate here to mention that the appearance of the International Review of Social History in 1956 was largely due to Professor Rüter's inspiring energy. To the members of the editorial staff, who enjoyed his whole-hearted guidance and co-operation, his death means a personal loss. 